\title{
BÀN VỀ SỰ DỊCH CHUYỂN TÂM TRÁI ĐÂTT TRONG VIỆC XÂY DỰNG KHUNG QUY CHIẾU QUỐC TẾ
}

\author{
NGUYẼ̃N CÔNG SƠN, NGUYẼ̃N TH!̣ THÚY HẦNG, VŨ DUY TÂN, \\ PHAN DOÃN THÀNH LONG, BÙI THỊ LÊ HOÀN, \\ VŨ TRUNG THÀNH, ĐÀO THI BÍCH HỒNG \\ Viện Khoa học Đo đạc và Bản đồ
}

\section{Tóm tắt:}

Dịch chuyển tâm của Trái đất được xem là một chủ đề quan trọng trong việc xây dựng và duy trì Khung quy chiếu Trái đất quốc tế (ITRF). Việc xác định độ lệch tâm của Trái đất là nền tảng để các nhà khoa học giải quyết các vấn đề gắn liền với hình dạng, kích thuớc và sụ thay đổi của Trái đất, nhu: sự dịch chuyển mảng kiến tạo, vùng địa chấn, sụ dịch chuyển của các vùng động đất, hiện tuợng băng tan, sự gia tăng của mưc nước biển... Bài báo này trên cơ sở tổng hợp một số kết quả nghiên cưu quốc tế liên quan đến ITRF sẽ nêu tóm tắt co bản về sự dịch chuyển của ITRF, phuơng pháp xác định độ lệch tâm của Trái đất, ảnh hưởng của sụ dịch chuyển tâm của Trái đất đến ITRF.

\section{Mở đầu}

Việc nghiên cứu và hiểu được quá trình động học của Trái đất là nền tảng cơ bản để định nghĩa về hệ thống tham chiếu mặt đất toàn cầu. Thêm vào đó, việc quan trắc các mảng kiến tạo, sự dịch chuyển của các vùng động đất, sự chuyển động của các khối chất lỏng trong lòng Trái đất, ảnh hưởng của biến đổi khí hậu và nước biển dâng, việc xác định chính xác vị trí điểm trên bề mặt Trái đất với độ chính xác lên đến vài $\mathrm{mm}$ [Métivier et al., 2020]. Những thành tựu đạt được này bằng việc sử dụng các công nghệ vệ tinh, tạo tiền đề cho việc xây dựng ITRF với độ chính xác cao. Từ khi ra đời tổ chức thế giới nghiên cứu về sự quay của Trái đất (IERS) từ năm 1988 đến nay, đã có 13 phiên bản về ITRF được công bố, bắt đầu là phiên bản ITRF88 và đến nay là ITRF2014. Và cũng theo IERS thì tâm của ITRF được định nghĩa là tâm của Trái đất tại thời điểm tính(tr. 97, Poutanen and Rózsa, 2020). ITRF được xem là một triển khai số của hệ quy chiếu Trái đất quốc tế ITRS (Métivier et al., 2020), vì vậy, việc xác định sự dịch chuyển tâm của Trái đất không chỉ được xem là vấn đề thiết yếu của hệ không gian trắc địa, địa vật lý, khoa học về vũ trụ mà còn được xem là một chủ đề quan trọng để xây dựng ITRF.

Sự dịch chuyển tâm của Trái đất có liên quan tới sự phân bố về vật chất của Trái đất. Nó cũng dễ bị thay đổi theo thời gian do khối chất lỏng ở trong lòng Trái đất. Các biến đổi trong hệ thống của Trái đất gồm các quá trình sự dịch chuyển của các mảng kiến tạo, ảnh hưởng của nước ngầm, sự tan chảy băng, sự tác động của khí quyển... được quan trắc và mô hình hoá để biểu diễn sự dịch chuyển tâm của Trái đất $[$ Babcock and Wilkins, 1986]. Số liệu quan trắc thường xuyên các vệ tinh tại các trạm đo vệ tinh cố định trên bề mặt Trái đất được dùng để theo dõi sự thay đổi chuyển động của Trái đất có liên quan đến ITRF tại các thời điểm quan trắc. Các công nghệ dùng để quan trắc sự dịch chuyển tâm của Trái đất được kể đến bao gồm: Đo khoảng cách lazer vệ tinh (SLR), đo bằng hệ thống định vị toàn cầu (GPS), đo bằng hệ thống định vị và xác định quỹ đạo dựa trên hiệu ứng Doppler (DORIS).

\section{Sự dịch chuyển tâm trái đất trong các} phiên bản ITRF

Từ phiên bản ITRF88 cho đến phiên bản ITRF2000, dữ liệu đầu vào được cung cấp bởi 
các trung tâm phân tích từ 4 công nghệ đo bao gồm: đo giao thoa đường đáy rất dài (VLBI), đo khoảng cách laser vệ tinh (SLR), đo bằng hệ thống vệ tinh dẫn đường toàn cầu (GNSS) và xác định quỹ đạo dựa trên hiệu ứng Doppler (DORIS). Sự đóng góp của việc đo bằng hệ thống vệ tinh dẫn đường toàn cầu (GNSS) được bắt đầu từ phiên bản ITRF91 bao gồm 21 trạm đo GPS, dữ liệu đo DORIS cũng được cải thiện độ chính xác theo thời gian, và đã có những đóng góp từ phiên bản ITRF94. Không giống như các phiên bản ITRF trước, ITRF2000 không bị giới hạn về dữ liệu không gian. Thêm vào đó, từ phiên bản ITRF2000 đã ước tính sự quay quanhtrục của6 mảng kiến tạo. Cũng giống như ITRF2000, ITRF2005 đã sử dụng dữ liệu đầu vào là chuỗi thời gian (dữ liệu đo hàng tuần VLBI) và các thông số định hướng của Trái đất. ITRF2008 được ra đời bằng việc kế thừa việc tính toán của ITRF2005 bằng việc sử dụng các thông số định hướng trái đất, dữ liệu đo: GNSS, VLBI, DORIS, đo laser đến vệ tinh. Bằng việc sử dụng trường vận tốc của 206 trạm đo, mô hình chuyển động tuyệt đối của 14 mảng kiến tạo chính (tương thích với ITRF2008) được tính toán với sai số trung phương có trọng số là $0.3 \mathrm{~mm} /$ năm [Métivier et al., 2020].

ITRF2014 được xem là một bước đột phá của các triển khai hệ thống quy chiếu Trái đất,các chuyển dịch phi tuyến ở các trạm được mô hình hoá (theo mùa hoặc chu kỳ nửa năm một lần) (Métivieret al., 2020). Ngoài ra còn có quá trình xử lý sau ở các vùng động đất. Sự dịch chuyển theo mùa được mô hình hóa bằng các hàm sin hoặc cosin. Mô hình xử lý động đất được tính toán dựa trên các thuật toán: Logarit, số mũ, kết hợp giữa Logarit và số mũ, số mũ kết hợp với số mũ. Sử dụng trường vận tốc của phiên bản ITRF2014 dựa trên 297 trạm đo, mô hình chuyển động tuyệt đối của 11 mảng kiến tạo được tính toán với độ chính xác là $0.3 \mathrm{~mm} / \mathrm{năm}$.

Để định nghĩa cho một ITRFcần có 14 thông số bao gồm: 3 về gốc toạ độ, 1 về tỷ lệ, 3 về định hướng, 7 thông sốlà các đạo hàm bậc nhất tương ứng theo thời gian của ITRF (tr. 3, [Métivier et al., 2020]). (Xem bảng 1)

Từ Bảng 1 ta có thể đánh giá được sự ổn định của các phiên bản ITRF trong suốt khoảng thời gian từ năm 2000 đến năm 2014. Từ bảng trên, chúng ta có nhận xét rằng từ ITRF2005, độ ổn định trung bình đạt $0.3 \mathrm{~mm} / \mathrm{năm}$. Giá trị lớn nhất là độ lệch của ITRF2000 so với ITRF2014 ở trục $\mathrm{Z}$ là $1.9 \mathrm{~mm} / \mathrm{năm}$. Các giá trị quan trắc cũng chỉ ra rằng giá trị ITRF2005 có giá trị đáng tin cậy cao [Métivier et al., 2020]. Sự dịch chuyển giữa ITRF2008 so với ITRF2005 tương ứng là -0.5 , -0.9 và -4.7 theo trục $X, Y$ và $Z$ tương ứng [Altamimi et al., 2011]. Đặc biệt là Khung quy chiếu Trái đất quốc tế ITRF2014 đã thể hiện đây là một mô hình chặt chẽ có tính ưu việt hơn so với hai phiên bản trước đó.

\section{Phương pháp nghiên cứu dịch chuyển tâm của trái đất từ các vệ tinh trắc địa}

Trường trọng lực của Trái đất được biểu diễn dưới dạng các hàm số điều hòavới các hệ số mức $\mathrm{n}$ bậc $\mathrm{m}\left(C_{\mathrm{nm}}, S_{\mathrm{nm}}\right)$, các hàm số này được sử dụngđể thể hiện sự phân bố khối lượng vật chất của Trái đất được xác định tích phân theo thể tích của toàn bộ Trái đất. Như vậy, tọa độ tâm Trái

Bảng 1: Tốc độ trôi các phiên bản ITRF trước đây so với phiên bản ITRF2014 (Métivier et al, 2020)

\begin{tabular}{|c|c|c|c|}
\hline & $\dot{T}_{x}(\mathrm{~mm} / \mathrm{năm})$ & $\dot{T}_{y}(\mathrm{~mm} / \mathrm{năm})$ & $\dot{T}_{z}(\mathrm{~mm} / \mathrm{năm})$ \\
\hline ITRF & & & \\
\hline 2000 & 0.1 & 0.1 & 1.9 \\
\hline 2005 & 0.3 & 0 & -0.1 \\
\hline 2008 & 0 & -0.1 & -0.02 \\
\hline
\end{tabular}


đất trong hệ quy chiếu được xác định bởi các hệ số: $C_{10}, C_{11}, S_{11}$ của hàm điều hòa cầu. Véc tơ tọa độ tâm Trái đất được xác định bởi công thức sau [Cheng et al., 2013]:

$$
\overrightarrow{r_{c m}}=a_{e} \sqrt{3}\left(C_{10}, C_{11}, S_{11}\right)
$$

Trong đó: $a_{e}$ là bán kính của Trái đất

Trong hệ quy chiếu địa tâm, tọa độ củatâm của Trái đất được xác định bởi cáchệ số khai triển ở mức 1 làbằng 0 . Gốc của hệ quy chiếu quán tính độ chính xác cao được chọn trùng với tâm của Trái đất. Véc tơ tọa độ địa tâm Trái đất $\vec{r}_{c m}$ đại diện cho sự thay đổi tức thời giữa tâm Trái đất và gốc hệ quy chiếu quán tính ITRF.

Dựa vào lý thuyết này, hai phương pháp chính có thể được tiếp cận:

Phương pháp 1: Phương pháp trực tiếp xác định dịch chuyển tâm Trái đất (Direct Methods) [tr. 1488, Vigue et al., 1992, tr. 45, 53, Wu et al., $2012 \ldots]$. Phương pháp này xác định quỹ đạo vệ tinh bay quanh Trái đất liên quan đến (trọng) tâm Trái đất CM (Center-of-Mass of the total Earth system) từ các điểm quan trắc vệ tinh (GNSS, SLR, DORIS) trên Trái đất (liên quan đến tâm của hình dạng Trái đất cứng CF (Center-ofFigure ofthe solid Earth surface).

Đối với phương pháp này xem gốc của các quỹ đạo vệ tinh chính là tâm của Trái đất $\mathrm{CM}$ (Center-of-Mass of the whole Earth system) được liên hệ với lý thuyết quỹ đạo động. Trong việc tính toán quỹ đạo chuyển động, trạm theo dõi vệ tinh và trạm theo dõi sự chuyển động của hệ toạ độ địa tâm được tính toán đồng thời. Hệ tọa độ của các trạm cũng sẽ được tính toán ngay tức thì trong hệ quy chiếu quán tính nơi ở đó có sự thay đổi của tâm trái đất. Công thức biến đổi đồng dạng Helmert7 tham số [Vigue et al. (1992)] được dùng để tính toán sự dịch chuyển tâm trái đất so với điểm gốc Khung quy chiếu ITRFyyyy từ dữ liệu đo trắc địa vệ tinh như GNSS, SLR, DORIS...:

$$
\mathrm{X}(\mathrm{t})=\bar{X}(t)+\left[\begin{array}{c}
T_{x}(t) \\
T_{y}(t) \\
T_{z}(t)
\end{array}\right]+\left[\begin{array}{ccc}
\Delta(t) & -R_{z}(t) & R_{y}(t) \\
R_{z}(t) & \Delta(t) & -R_{x}(t) \\
-R_{y}(t) & R_{x}(t) & \Delta(t)
\end{array}\right] \bar{X}(t)
$$

Trong đó: $\mathrm{X}(\mathrm{t})$ : toạ độ điểm xác định từ dữ liệu đo trắc địa vệ tinh như GNSS

$\bar{X}$ : tọa độ điểm trong ITRFyyyy

$\Delta$ : độ lệch hệ số tỷ lệ giữa hai hệ tọa độ chuyển đổi.

$T_{x}, T_{y}, T_{z}$ : độ lệch tâm của Trái đất so với điểm gốc của ITRFyyyy

$R_{x}, R_{y}, R_{z}$ : các tham số quay giữa hai hệ tọa độ

Các thông số chưa biết bao gồm: $\Delta, T_{x}, T_{y}$, $T_{z}, R_{x}, R_{y}, R_{z}$, được tính toán bằng phương pháp bình sai.

Các công nghệ: Đo khoảng cách lazer vệ tinh (SLR), đo bằng hệ thống vệ tinh dẫn đường toàn cầu (GNSS), đo bằng hệ thống định vị và xác định quỹ đạo dựa trên hiệu ứng Doppler có thể sử dụng phương pháp này. Tuy nhiên, đo khoảng cách lazer vệ tinh được xem có độ tin cậy cao nhất trong việc xác định độ lệch tâm của Trái đất có liên quan tới ITRF.

Phương pháp 2: Phương pháp nghịch đảo (Inversion Methods) xác định các hệ số khai triển thế trọng trường Trái đất: $C_{10}, C_{11}, S_{11}$ theo các hàm cầu.

Theo lý thuyết, quỹ đạo của vệ tinh là quỹ đạo của khung tham chiếu quán tính có tâm trùng với tâm trái đất. Ở trong hệ quy chiếu quán tính này, hệ số bậc 1 khai triển của hàm điều hoà $\left(C_{11}, S_{11}, C_{10}\right)$ bằng 0 . Tâm của Trái đất cố định gắn liền với Trái đất trong không gian. Khung tham chiếu gắn liền với Trái đất được gọi là khung quy chiếu Trái đất. Ở khung quy chiếu Trái đất, tâm của Trái đất bị thay đổi do ảnh hưởng của chuyển dịch cực Trái đất và các chuyển động của mảng kiến tạo trên toàn cầu. Ở khung quy chiếu Trái đất, hệ số khai triển bậc 1 
của hàm điều hoà $\left(C_{11}, S_{11}, C_{10}\right)$ được xác định như sau [Heiskanen and Mortiz, 1967]:

$$
\left\{\begin{array}{l}
R C_{11}=X_{g} \\
R S_{11}=Y_{g} \\
R C_{10}=Z_{g}
\end{array}\right\}
$$

Trong đó $X_{g}, Y_{g}, Z_{g}$ là giá trị tọa độ Đề các của tâm Trái đất trong khung quy chiếu Trái Đất, $\mathrm{R}$ là hằng số phụ thuộc vào bán kính trung bình Trái đất và số Love.

\section{4. Ảnh hưởng của độ lệch tâm trái đất đến ITRF}

Nhóm tác giả gồm M.K Cheng, J.C Ries và R.D.Tapley đã phân tích độ lệch tâm của Trái đất bằng phương pháp đo khoảng cách lazer vệ tinh (SLR) [Cheng et al., 2013]. Dữ liệu được đo trong vòng 18 năm từ tháng 11 năm 1992 cho đến tháng 12 năm 2000. Trong khoảng thời gian từ năm 2002 đến năm 2010 thì dữ liệu được thu thập hàng tháng.

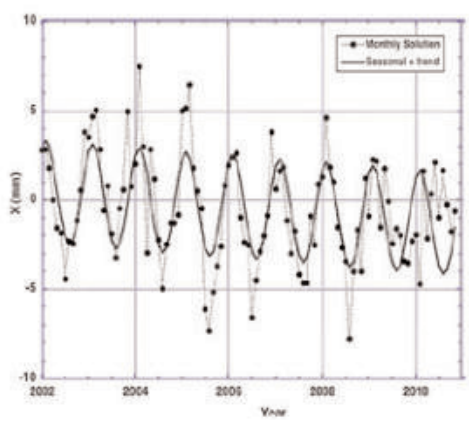

Hình 1: Sụ biến thiên tâm của Trái đất theo truc $X$

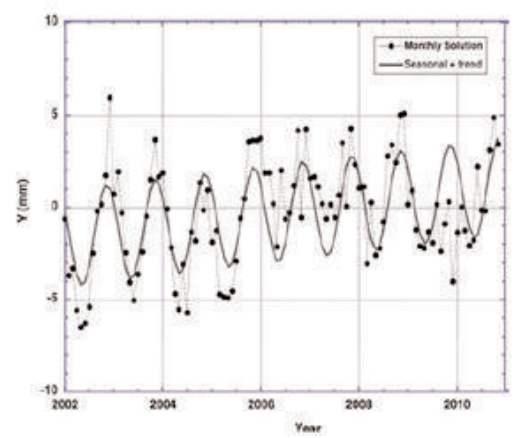

Hình 2: Sụ biến thiên tâm của Trái đất theo truc $Y$

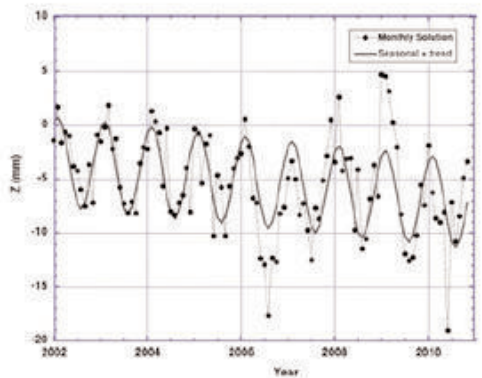

Hình 3: Sự biên thiên tâm của Trái đât theo truc $Z$

Ở hình $1,2,3$ cho chúng ta thấy tốc độ dịch chuyển hàng năm theo các trục $\mathrm{X}, \mathrm{Y}, \mathrm{Z}$ ước tính là $0.2,0.3$ và $0.5 \mathrm{~mm} /$ năm. Chấm đen là kết quả hàng tháng và đường liền màu đen là xu thế và biến thiên theo mùa.

Kết quả từ dữ liệu đo SLR hàng tháng từ năm 2002-2010 được so sánh với kết quả dữ liệu đo hàng tuần từ 1992-2008, cùng với nghiên cứu của Collilieux et al (2009). ((ký hiệu ILRS-1), nghiên cứu của Altamimi et al (2011) ký hiệu ILRS-2trong việc phát triển ITRF2008 và mô hình dự báo bậc 1dựa vào số liệu GPS/GRACE trong nghiên cứu của [Wu et al., 2010]: (Xem bảng 2)

Bảng 2 thể hiện rằng kết quả dữ liệu đo SLR hàng tuần từ 1992-2008 có tương quan với kết quả dữ liệu đo từ nghiên cứu ILRS-2. Tuy nhiên khi so sánh đối với nghiên cứu từ ILRS-1, trục $\mathrm{Y}$ có độ tương quan không được tốt. Kết quả dữ liệu đo SLR hàng tháng trong giai đoạn từ 20022010 có độ tương quan tốt với mô hình bậc 1 ở trục $\mathrm{Y}$ và trục $\mathrm{Z}$. Sự không tương quan ở trục $\mathrm{X}$ được giải thích do ảnh hưởng của sự phân bố các trạm SLR (theo nghiên cứu của Collilieux và cộng sự 2009) dẫn tới sự biến đổi lớn ở trục X.

Ở trong nghiên cứu này, sự dịch chuyển của trục $\mathrm{X}, \mathrm{Y}, \mathrm{Z}$ tại thời điểm năm 2005 trong ITRF2005 tương ứng là $-0.2,-0.7$ và $-4.8 \mathrm{~mm}$. Theo nghiên cứu của Altamimi và nhóm cộng sự (2011) ước tính sự dịch chuyển của ITRF2008 so với ITRF2005 tại thời điểm năm 2005 tương ứng là $-0.5,-0.9$ và $-4.7 \mathrm{~mm}$. Hai kết quả nghiên cứu này, có độ tương quan cao đã chứng tỏ việc 
Bảng 2: Độ lệch tâm của Trái đất được quan trắc tù các vệ tinh khác nhau

\begin{tabular}{|l|c|c|c|c|c|c|}
\hline & & $\mathrm{x}$ & & $\mathrm{Y}$ & & $\mathrm{Z}$ \\
\hline & $\begin{array}{c}\text { Độ 1ệch } \\
(\mathrm{mm})\end{array}$ & Pha thời gian (s) & $\begin{array}{c}\text { Độ lệch } \\
(\mathrm{mm})\end{array}$ & Pha thời gian (s) & $\begin{array}{c}\text { Độ lệch } \\
(\mathrm{mm})\end{array}$ & Pha thời gian (s) \\
\hline SLR-hàng tuần & $2.7 \pm 0.2$ & $40 \pm 2$ & $2.8 \pm 0.2$ & $323 \pm 2$ & $5.2 \pm 0.2$ & $30 \pm 3$ \\
\hline ILRS-1 & $2.7 \pm 0.3$ & $45 \pm 4$ & $3.8 \pm 0.2$ & $327 \pm 4$ & $3.6 \pm 0.4$ & $4 \pm 7$ \\
\hline ILRS-2 & $2.6 \pm 0.1$ & $40 \pm 3$ & $3.1 \pm 0 / 1$ & $315 \pm 2$ & $5.5 \pm 0.3$ & $22 \pm 10$ \\
\hline SLR-tháng & $2.9 \pm 0.4$ & $35 \pm 3$ & $2.6 \pm 0.2$ & $306 \pm 3$ & $4.2 \pm 0.2$ & $33 \pm 2$ \\
\hline Mô hình bậc 1 & $1.8 \pm 0.2$ & $49 \pm 3$ & $2.7 \pm 0.2$ & $325 \pm 3$ & $4.2 \pm 0.2$ & $31 \pm 3$ \\
\hline
\end{tabular}

nghiên cứu sự dịch chuyển tâm của Trái đất là vấn đề cơ bản và thiết yếu trong việc xác định ITRF.

\section{Kết luận}

Việc xác định chính xác sự dịch chuyển tâm của Trái đất là yếu tố quan trọng trong việc xác định sự biến đổi các khối vật chất trên bề mặt cũng như trong lòng Trái đất. Sự dịch chuyển tâm của Trái đất là nền tảng cơ bản để định nghĩa và duy trì Khung quy chiếu Trái đất quốc tế. Việc quan trắc sự dịch chuyển tâm của Trái đất qua các thời kỳ khác nhau chính là cơ sở cho việc xây dựng các phiên bản ITRF. $\bigcirc$

\section{Tài liệu tham khảo}

[1]. Zuheir Altamimi, Xavier Collilieux, Laurent Métiver (2011), ITRF2008: an improved solution of the international terrestrial reference frame, $J$ Geod (2011) 85:457-473, DOI 10.1007/s00190-011-0444-42011.

[2]. Alice K. Babcock and George A.Wilkins (eds.) (1986), The earth's rotation and reference frame for geodesy and geodynamics. Processing of the $128^{\text {th }}$ symposium of the international astronomical union, held in Coolfont, West Virginia,USA, 20-24 October 1986.

[3]. M.K Cheng, J.C Ries and B.D Tapley (2013), Geocenter Variations from analysis of SLR data. In: Altamimi Z., Collilieux X. (eds)Reference Frames for Applications in Geosciences, International Association of Geodesy Symposia, vol138. Springer, Berlin, Heidelberg. https://doi.org/10.1007/978-3-64232998-2_4
[4]. Collilieux X, Altamimi Z, Ray J, Van Dam T, Wu X (2009), Effect of the satellite laser ranging network distribution on geocenter motion estimation. J Geophys Res 114: B04402.

[5]. Heiskanen, W.A, Moritz, H., 1967, Physical Geodesy, W.H Freemanand and Company, San Franciscoand London.

[6]. Laurent Métivier, Zuheir Altamimi, Hélèn Rouby. Past and present ITRF solutions from geophysical perpective. Advances in space research, 2020 , https://doi.org/10.1016/j.asr.2020.03.031.

[7]. Markku Poutanen and Szabolcs Rózsa (eds.) (2020), TheGeodesist'sHandbook2020, Journal of Geodesy, Vol. 94 - No. 11 - November 2020, pp. 343.

[8]. Vigue, Y., S.M. Lichten, G. Blewitt, M. B. Heflin, and R. P. Malla (1992), Precise determination Earth's Center of Mass using Measurements from the Global Positioning System, Geophys. Res. Lett., 19, No. 14, 14871490, July 24, 1992.

[9]. Wu X, Heflin M, Schotman H, Vermeersen B, Dong D, Gross R, Ivins E, Moore A, Owen S (2010), Simultaneous estimation of global present-day water transport and glacial isotatic adjustment. Nat Geosci. 3, September, 642-646,doi:10.1038/NGEO938.

[10]. Xiaoping Wu, Jim Ray,Tonie van Dam (2012), Review: "Geocenter motion and its geodetic and geophysical implications", Journal of Geodynamics 58 (2012) 44-61.O 


\section{Summary}

\section{Assesment of geocentre motion in building International Terrestrial Reference Frame}

Nguyen Cong Son, Nguyen Thi Thuy Hang, Vu Duy Tan, Phan Doan Thanh Long, Bui Thi Le Hoan, Vu Trung Thanh, Dao Thi Bich Hong

Vietnam Intitude of Geodesy and Cartography

Geocentre motion is a significantfactor inconstructing the International Terrestrial Reference Frame. The motion of the Earth's centre is fundamental to addressing scientific challenges pertaining to the quantification of changes that are affecting the Earth system involving plate tectonics, coseismic and postseismic deformations, current ice melting, sea level rise... This paper discusses the main drift origin of the different versions of the International Terrestrial Reference Frame (ITRF), the method for estimating geocentre motions from space geodetic observations and the effects of the geocentre motion to defining the origin of the International Terrestrial Reference Frame. The determination of the variation of geocentre is a crucial important topic as well as determination and maintenance of the ITRF.O

THÀNH LẬP BẢN ĐỒ HỆ THỐNG SỦ̉ DỤNG ĐẤT.....

(Tiếp theo trang 41)

[10]. Hole F.D. and Campbell J.B. (1985), Soil Landscape Analysis, Government Institutes.

[11]. Nguyễn Thế Thôn (1995), "Một số vấn đề địa mạo - thổ nhưỡng và thành lập bản đồ địa mạo thổ nhưỡng cho quy hoạch phát triển kinh tế”, Tạp chí Khoa học đất. Tập 5.

[12]. Đào Đình Bắc (1997) Địa mạo - thổ nhưỡng, nội dung và ý nghĩa của nó đối với việc quy hoạch sử dụng đất. Tạp chí Khoa học ĐHQG Hà Nội, ĐHKHTN, Sô 4, trang 16 - 22.

thành lập bản đồ, địa mạo - thổ nhưỡng làm cơ sở khoa học cho sử dụng lâu bền tài nguyên môi trường đất Việt Nam. Luận án Tiến sĩ Địa lý, Hà Nội -2002.

[14]. Phan Thị Thanh Hải, Đặng Văn Bào (2016). Đánh giá thích nghi sinh thái cảnh quan địa mạo - thổ nhưỡng cho phát triển cây thanh long ruột đỏ Long Định 1 tại khu vực chân núi Ba Vì, huyện Ba Vì, Hà Nội. Tạp chí KH Nông nghiệp Việt Nam 2016, Tập 14, Số 11, trang 1789-1800. O

[13]. Vũ Ngọc Quang (2002), Nghiên cứu

\section{Summary}

Making land use system map of phu my district, binh dinh province based on soil-geomophological landscape approach

Nguyen Trong Doi ${ }^{1}$, Nguyen Cao Huan ${ }^{2}$, Tran Van Tuan ${ }^{2}$

${ }^{1}$ Faculty of Natural Sciences, Quynhon University

${ }^{2}$ Faculty of Geography, VNU University of Science, VNU, Hanoi

Land mapping units are still considered the most basic object in land evaluation to indicate the suitability of land use types in agricultural production. However, the assessment based on land units has not yet assessed the synthesis of socio-economic and environmental factors as well as solving the problem of multi-scale assessment of the territory. This study is based on the soil-geomorphological landscape approach, which is a new research direction to determine construction criteria, hierarchical land units and land use classification, thereby establishing a map of the land use system. agricultural land for Phu My district, Binh Dinh province. The land use system shows the relationship according to the vertical structure of the geographical landscape of the constituent elements and will be used as a unit to assess the suitability of the land use type in its land use system. $\bigcirc$ 